\title{
ERJ
}

Engineering Research Journal

Faculty of Engineering

Minoufiya University

\section{PREDICTION OF THE FLOW FIELD IN VENTILATED ROOMS USING DIFFERENT TURBULENCE MODELS}

\author{
T. I. Sabry , N. H. Mahmoud, A. A. Abdel-Hamied, and A. A. Hussien \\ Mechanical Power Engineering Department, Faculty of Engineering, \\ Minoufiya University, Shebin El-kom, Egypt \\ E-mail:as_amien@yahoo.com
}

\begin{abstract}
This paper utilizes four turbulence models to predict the airflow field inside ventilated rooms. These models are namely the standard $\mathrm{k}-\varepsilon$, RNG based $\mathrm{k}-\varepsilon$, Low-Reynolds number and extended $\mathrm{k}-\varepsilon$ (Chen-Kim) models. The computational fluid dynamics (CFD) model is used to solve the basic equations of mass and momentum conservation in the primitive form together with the equations of turbulence model. A model room is used to obtain some flow characteristics such as velocity and turbulent kinetic energy distributions along the flow field. To test the ability of different turbulence models for predicting the airflow field, the numerical results from the proposed models are compared with the published experimental results. To extra validation, a suitable room with inlet and outlet openings of air is designed and fabricated to obtain the velocity distribution. Also, numerical findings are compared to the measured results of vertical velocity distribution inside ventilated rooms. Comparisons declare that the extended standard k- $\varepsilon$ (Chen-Kim) model can be used to predict the airflow field inside closed rooms equipped with forced ventilation systems more accurately when compared to other different turbulence models.

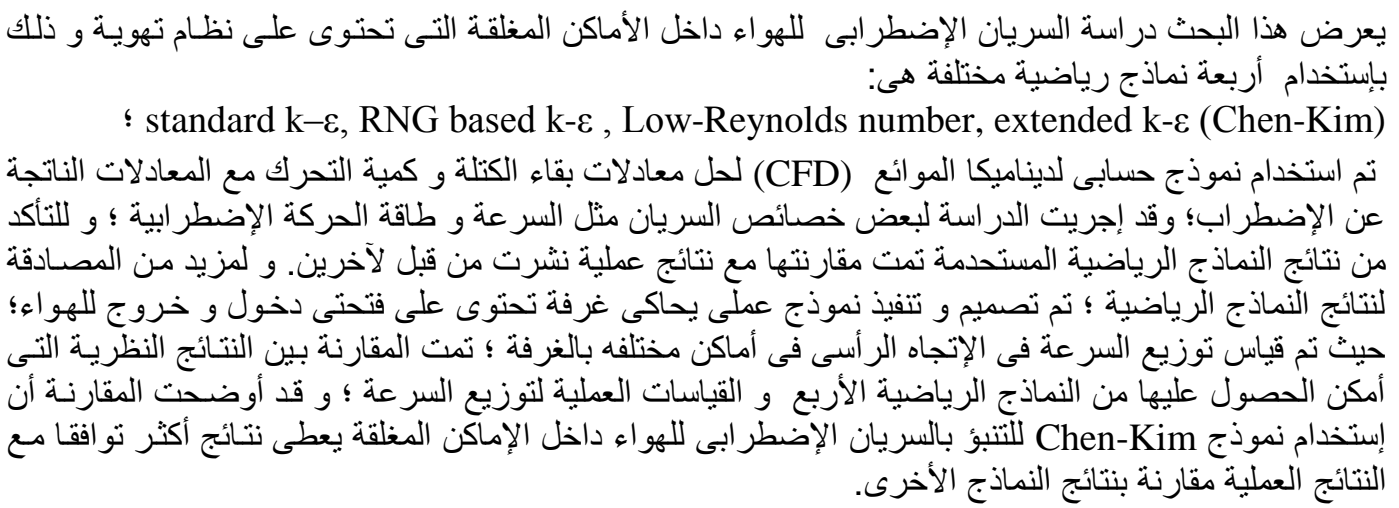

Keywords: Room Ventilation, Turbulence models, Numerical simulation.

\section{INTRODUCTION}

Simulation of air movement in ventilated rooms is essential before starting the design of a ventilation system. The object of this design is to create an acceptable climate with suitable distributions of velocity, temperature and concentration of contaminants. The process of creating good indoor climate can, basically, be divided into two categories. The first one involves ventilation for a good air quality and obtain one comprises heating or cooling for thermal comfort. Therefore, many researchers carried out investigations of airflow field. Davidson [1] calculated velocity and concentration fields for a two-dimensional, isothermally ventilated room. During this study the air flow field was solved using the standard k- $\varepsilon$ turbulence model. LU and Howarth [2] presented numerical model of the air movement and aerosol particles deposition and migration in two interconnected ventilated zones. Standard k- $\varepsilon$ twoequation model was used in this paper to predict the air flow. Comparison of different $\mathrm{k}-\varepsilon$ models for indoor air flow computations was carried out by Chen [3]. The comparison indicated that the results of simulation of indoor airflow using RNG based $k-\varepsilon$ are better than standard $k-\varepsilon$. A two-layers turbulence model for simulating indoor airflow was investigated and used by $\mathrm{Xu}$ and Chen $[4,5]$. The study had developed a two-layer near-wall turbulence model for indoor airflow. Davidson and Nielsen [6] presented numerical study of flow in a threedimensional ventilated room. Large eddy simulation 
model was applied to predict the airflow field. Model results showed that using dynamic sub-grid model gives results in good agreement with the experimental data. Numerical and experimental study of 3-D analysis of air flow and contaminate particle transport in a partitioned enclosure were carried out by Chung [7]. Large eddy simulation of indoor airflow with a filtered dynamic sub-grid scale model was illustrated by Zhang and Chen [8]. The model was used to predict the distributions of indoor airflow of complex flow without non-directional characteristics, direction, such as airflow with natural, forced, and mixed convection in a room. Nikas, et al. [9] presented a numerical study of a naturally cross-ventilated building in $\mathrm{k}-\omega$ to predict the flow field. Savrakakis and Markatos [10] gave simulation of airflow in one and two room enclosures containing a fire source using both Standard k- $\varepsilon$ and RNG based $\mathrm{k}-\varepsilon$ models. The results concluded that RNG based k- $\varepsilon$ model gives a good prediction with presence of fire source inside the room.

From the previous presentation, it can be observed that k- $\varepsilon$ models are extensively used for the prediction of airflow in rooms. Chen and Kim [11] developed standard $\mathrm{k}-\varepsilon$ model by adding a source term to the dissipation rate equation. This developed model was not widely used to predict the airflow inside ventilated room. Full-scale experimental data and computational fluid dynamics (CFD) methods were used to determine the accuracy of four different turbulence models namely, standard $\mathrm{k}-\varepsilon, \mathrm{k}-\varepsilon$ renormalization group ( $\mathrm{RNG}), \mathrm{k}-\varepsilon$ realizable and Reynolds stress models (RSM)] by Bartzanas et al. [12]. Numerical results were compared with the experimental data. The comparison showed agreement, especially when the RNG based k- $\varepsilon$ turbulence model was used.
The objective of this paper is to compare the accuracy of Standard k- $\varepsilon$, RNG based k- $\varepsilon$, Chen-Kim $\mathrm{k}-\varepsilon$ and low-Reynolds standard $\mathrm{k}-\varepsilon$ models in predicting the airflow field in ventilated rooms.

\section{AIR FLOW MODELLING}

The main air flow modelling principles include turbulence modelling, finite volume discreatization, boundary condition, computational grid and numerical solution. The transport equations for continuity, momentum and the turbulent kinetic energy $(\mathrm{k})$ and its dissipation rate $(\varepsilon)$ have the general form [13] and given by:

$$
\begin{gathered}
\frac{\partial}{\partial t}(\rho \phi)+\frac{\partial}{\partial x}(\rho u \phi)+\frac{\partial}{\partial y}(\rho v \phi)+\frac{\partial}{\partial z}(\rho w \phi)= \\
\frac{\partial}{\partial x}\left(\Gamma_{\phi} \frac{\partial \phi}{\partial x}\right)+\frac{\partial}{\partial y}\left(\Gamma_{\phi} \frac{\partial \phi}{\partial y}\right)+\frac{\partial}{\partial z}\left(\Gamma_{\phi} \frac{\partial \phi}{\partial z}\right)+S_{\phi}
\end{gathered}
$$

Here, $\Phi$ is the dependent variable. While, $S_{\Phi}$ is the source term which has different expressions for different transport equations. The convection and diffusion terms for all the transport equations are identical, with $\Gamma_{\Phi}$ representing the diffusion coefficient for scalar variables and the effective viscosity $\mu_{e}$ for vectorial variables, i.e. velocities. The characteristics of the transport equations are extremely useful when the equations are discretized (reduced to algebraic equations) and solved numerically. In fact this equation also represents the continuity equation when $\Phi=1$ and $S_{\Phi}=0$. Table (1) gives the expressions for the source terms $S_{\Phi}$ for each dependent variable that are needed in solving ventilation problems.

In the transport equations for turbulent flows, the turbulent stresses or turbulent diffusion terms are added to the laminar stresses or laminar diffusion terms using the concept of effective viscosity or effective diffusion coefficients.

Table 1, Source terms in the transport equations

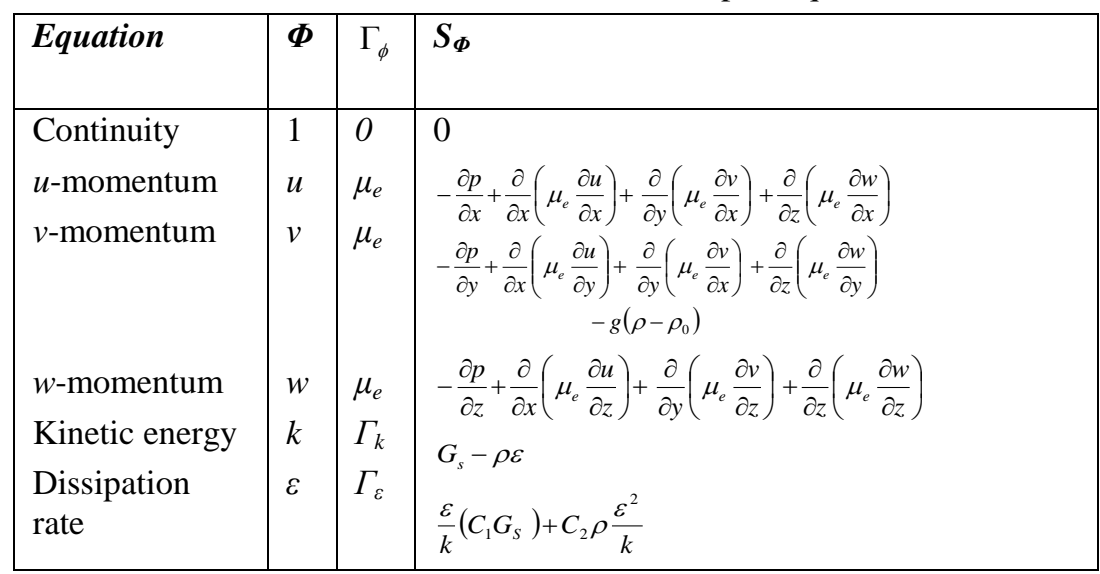


The effective viscosity coefficient, $\mu_{e}$, is defined by:

$$
\mu_{e}=\mu+\mu_{t}
$$

The effective diffusion coefficient for the scalar term $\Gamma_{e}$, is:

$$
\Gamma_{e}=\Gamma+\Gamma_{t}=\mu+\frac{\mu_{t}}{\sigma_{t}}
$$

Where, $\sigma_{\mathrm{t}}$ is turbulent Prandtl or Schmidt number of the fluid.

The production term $\mathrm{G}_{\mathrm{s}}$ is defined by:

$$
\begin{array}{r}
G_{S}=\mu_{t}\left(2\left[\left(\frac{\partial u}{\partial x}\right)^{2}+\left(\frac{\partial v}{\partial y}\right)^{2}+\left(\frac{\partial w}{\partial z}\right)^{2}\right]+\left(\frac{\partial u}{\partial y}+\frac{\partial v}{\partial x}\right)^{2}\right. \\
\left.+\left(\frac{\partial u}{\partial z}+\frac{\partial w}{\partial x}\right)^{2}+\left(\frac{\partial v}{\partial z}+\frac{\partial w}{\partial y}\right)^{2}\right)
\end{array}
$$

\section{TURBULENCE MODELS}

The effective and eddy viscosities are calculated for the different suggested models as follows:

\subsection{Standard $k$ - $\varepsilon$ Model}

$$
\left.\begin{array}{l}
\mu_{e}=\mu+\mu_{t}, \\
\mu_{t}=C_{\mu} \rho \frac{k^{2}}{\varepsilon}
\end{array}\right\}
$$

\subsection{RNG based $k-\varepsilon$ Model}

$$
\mu_{e}=\mu\left[1+\sqrt{\frac{C_{\mu} \rho}{\mu}} \frac{k}{\sqrt{\varepsilon}}\right]^{2}
$$

The Prandtl numbers, $\sigma_{\mathrm{k}}$ and $\sigma_{\varepsilon}$ in $\mathrm{k}-\varepsilon$ equations are modified and computed as follows:

$$
\left|\frac{\lambda-1.3929}{\lambda_{0}-1.3929}\right|^{0.6321}\left|\frac{\lambda+1.3929}{\lambda_{0}+1.3929}\right|^{0.3679}=\frac{\mu}{\mu_{e}}
$$

Where, $\lambda=1 / \sigma_{\mathrm{k}}=1 / \sigma_{\varepsilon}=1 / \sigma_{\mathrm{t}}$ and $\lambda_{\mathrm{o}}=1 / \sigma(\sigma$ being the laminar Prandtl number for the fluid).

The rate of strain $\mathrm{R}$ for RNG based $\mathrm{k}-\varepsilon$ model is expressed as given in [14] by:

$$
R=\frac{C_{\mu} \eta^{3}\left(1-\eta / \eta_{0}\right)}{1+\beta \eta^{3}} \frac{\varepsilon^{2}}{k}
$$

where, $\beta=0.015, \eta_{0}=4.38$ and $\eta$ is calculated as:

$$
\eta=\frac{k}{\varepsilon}\left(2 S_{i j}^{2}\right)^{\frac{1}{2}}
$$

and $\mathrm{S}_{\mathrm{ij}}$ is the tensor notation, computed as follows:

$$
S_{i j}=\frac{1}{2}\left(\frac{\partial u_{i}}{\partial x_{j}}+\frac{\partial u_{j}}{\partial x_{i}}\right)
$$

\subsection{Low-Reynolds $\boldsymbol{k}$ - $\varepsilon$ Model}

The low-Reynolds $\mathrm{k}-\varepsilon$ model uses the damping functions and the extra source terms. The source terms and damping functions are calculated as given in [15] as:

$$
\mu_{t}=f_{\mu} C_{\mu} \rho \frac{k^{2}}{\varepsilon}
$$

The damping function $f_{\mu}$ is calculated from the equation:

$$
f_{\mu}=\exp \left[-2.5 /\left(1+R_{T} / 50\right)\right]
$$

Where, $R_{T}=\rho k^{2} / \mu \varepsilon$ is the turbulent Reynolds number.

The turbulent kinetic energy $(\mathrm{k})$ and the dissipation rate $(\varepsilon)$ equations have additional source terms D and E. These terms are calculated as follow:

$$
\left.\begin{array}{l}
D=2 \frac{\mu}{\rho}\left(\frac{\partial \sqrt{k}}{\partial y}\right)^{2}, \\
E=2 \frac{\mu \mu_{t}}{\rho^{2}}\left(\frac{\partial^{2} u}{\partial y^{2}}\right)^{2}
\end{array}\right\}
$$

\subsection{Chen-Kim Model}

An extended $\mathrm{k}-\varepsilon$ turbulence model had been proposed and tested by Kim and Chen [11]. An extra time scale had been added in the construction of the transport equation of the rate of dissipation of the turbulent kinetic energy. The source term added to the dissipation rate equation represents the energy transfer rate from large scale turbulence to small scale turbulence controlled by the production range time scale and the dissipation rate time scale as shown in next equation:

$$
\begin{aligned}
& \rho u \varepsilon_{x}+\rho v \varepsilon_{y}+\rho w \varepsilon_{z}-\left[\left(\mu_{t} / \sigma_{k}\right) \varepsilon_{x}\right]_{x}-\left\lfloor\left(\mu_{t} / \sigma_{k}\right) \varepsilon_{y}\right]_{y} \\
& -\left[\left(\mu_{t} / \sigma_{k}\right) \varepsilon_{z}\right]_{z}=\rho\left(C_{1} p_{r} \varepsilon / k+-C_{2} \varepsilon^{2} / k\right)+\underbrace{C_{3} p_{r}^{2} / \rho k}_{\text {newsourceterm }}
\end{aligned}
$$

This modified form of $\varepsilon$ equation is widely used for the fully developed flow in pipes and jets flow. It results in an energy transfer function which had been found to be more effective than that of standard k- $\varepsilon$. The constants of the turbulence models are given in table (2).

Table 2, Constants of turbulence models

\begin{tabular}{|lcccccc|}
\hline Model & $C_{\mu}$ & $\sigma_{k}$ & $\sigma_{\varepsilon}$ & $C_{1}$ & $C_{2}$ & $C_{3}$ \\
\hline Standard k- $\varepsilon$ & 0.09 & 1.0 & 1.3 & 1.44 & 1.92 & - \\
RNG model & 0.085 & \multicolumn{2}{c}{ Eq.(7) } & 1.42 & 1.68 & - \\
Low Re model & 0.09 & 1.0 & 1.3 & 1.44 & 1.92 & - \\
Chen-Kim model & 0.09 & 0.75 & 1.15 & 1.15 & 1.9 & 0.25 \\
\hline
\end{tabular}

\section{BOUNDARY CONDITIONS}

The numerical solution precision deeply depends on applying accurate boundary conditions. These conditions are integrated within the numerical model. In the present work, there are three sets of boundary conditions, namely: inlet, outlet conditions and wall boundary conditions. 


\section{- Inlet conditions}

The inlet conditions are defined using prescribed distributions of velocity, turbulence kinetic energy and dissipation rate. These conditions depend upon the turbulence intensity at inlet. The turbulence intensity, I, is defined as the ratio of the root meansquare of the velocity fluctuations, $\sqrt{\overline{u^{\prime 2}}}$, to the mean flow velocity $\bar{u}$. For the inlet turbulence intensity a value of 0.05 is used. For developing flows, the inlet conditions include uniform velocity profile with the inlet kinetic energy and dissipation rate being given by [12] as:

$$
\left.\begin{array}{l}
k=\frac{3}{2} I u_{0}^{2}, \\
\varepsilon=C_{\mu}^{3 / 4} \frac{k^{3 / 2}}{l}
\end{array}\right\}
$$

Where, $l$ is turbulence length scale.

\section{- Outlet conditions}

The outlet conditions assumed that the pressure outlet is equal to atmospheric pressure and the change of any parameters with respect to $\mathrm{x}$-direction is equal to

$$
\frac{\partial \phi}{\partial n}=0.0
$$

Where, $\mathrm{n}$ is the normal direction of outlet flow boundary.

\section{- Wall conditions}

No-slip boundary conditions are applied along the solid walls. In the near-wall region, the standard $\mathrm{k}-\varepsilon$, RNG based $\mathrm{k}-\varepsilon$, and Chen-Kim models employ a wall function. Based on the log-law of the wall and assuming equilibrium conditions in the turbulent boundary layer, the following expressions can be derived:

$$
\left.\begin{array}{ll}
\tau_{w}=\mu \frac{\partial u}{\partial y}=\mu \frac{u_{P}}{\delta} & y^{+} \leq 11.65 \\
\tau_{w}=\frac{\kappa C_{\mu}^{0.25} \rho u_{P} \sqrt{\kappa_{P}}}{\operatorname{In}\left(E y^{+}\right)} & y^{+}>11.65
\end{array}\right\}
$$

Where, $\kappa$ is the von Karman constant equals 0.41 [16].

Instead of the function used in the previous models, but the low Reynolds $\mathrm{k}-\varepsilon$ model uses damping function. Therefore, it solves the flow field directly up to the wall.

The model room is used to determine some flow parameters such as velocity and turbulent kinetic energy distributions along flow the field. The numerical results of these parameters will be compared with published experimental data to select the suitable turbulence model from the different turbulence models. The dimensions of model room are $(1 \times 1 \times 1) \mathrm{m}^{3}$ as shown in Fig. 1. The room has an inlet and an outlet opening. These openings are made in opposite sides. The inlet opening is located in the center of the front face with dimensions of $(20$ $\mathrm{cm} \times 20 \mathrm{~cm}$ ), while the outlet opening lies in the opposite side with dimensions of $(50 \mathrm{~cm} \times 25 \mathrm{~cm})$.

\section{NUMERICAL METHOD}

The standard k- $\varepsilon$, RNG based $\mathrm{k}-\varepsilon$ and lowReynolds $\mathrm{k}-\varepsilon$ models were used to predict the air flow inside ventilated rooms. During this study the extended (Chen-Kim) $\mathrm{k}-\varepsilon$ model will be used as a turbulence model of the flow filed through the ventilated room. The extended $\mathrm{k}-\varepsilon$ model is programmed and added to the CFD software used to solve the flow filed domain. A CFD program, FLUENT 6.3 [17], has been used to solve the time conservation equations together with the corresponding boundary conditions. The space of the room is divided into non staggered computational cells $(100 \times 100 \times 100)$. Figure 2 shows the computational grid. The discrete equations were solved with the SIMPLE algorithm (Patankar 1980). The convergence criteria at each time step were selected to ensure the total normalized residual to be less than 0.00001 for flow properties.

\section{EXPERIMENTAL WORK}

The experimental setup consists of a model room, ventilation system and measuring devices. These devices are used to measure the vertical mean velocity distribution at different positions. The measured velocities are compared to the numerical results of investigated turbulence models. The model room is made of wood with two sides of glass as shown in Fig. 3.

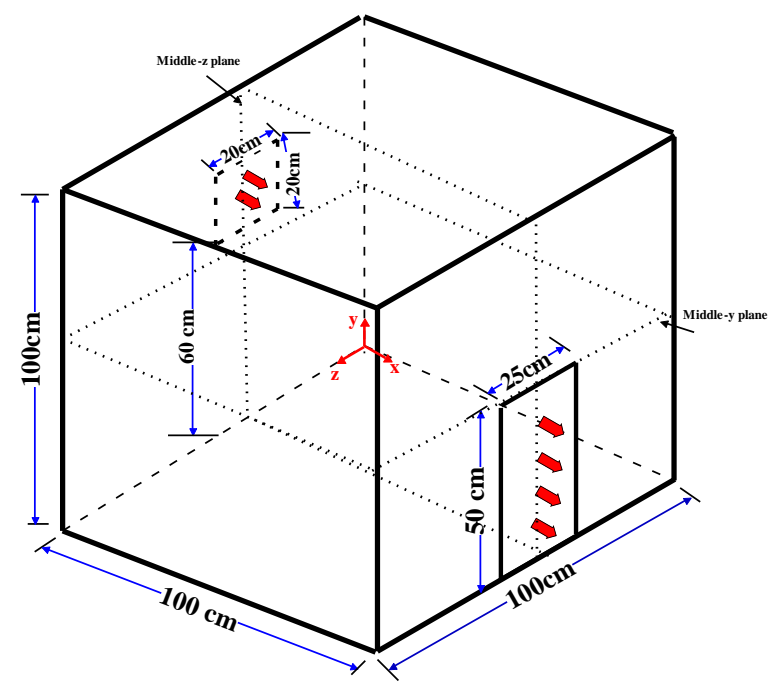

Fig. 1 The model room 


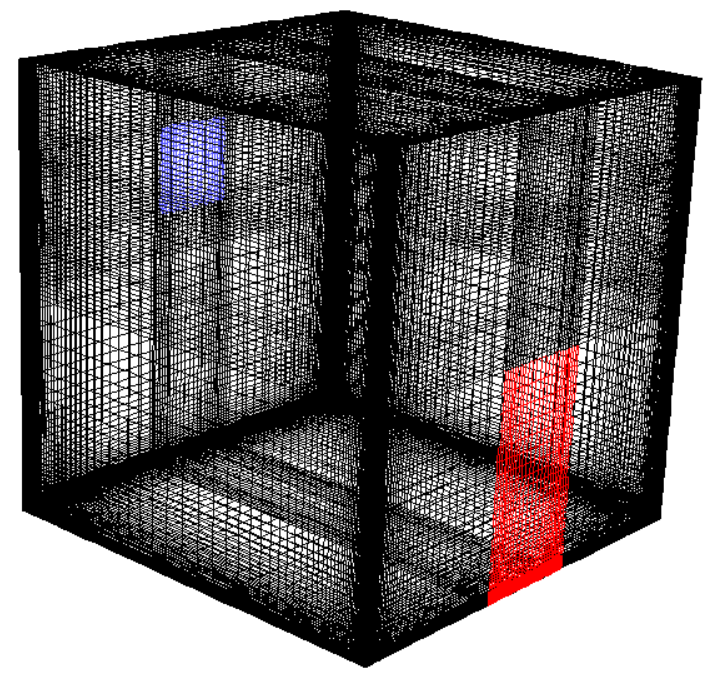

Fig. 2 Computational grid

The room dimensions are (1m x $1 \mathrm{~m} \times 1 \mathrm{~m})$. Electrical forced fan is used to move the air in the ventilation system. A control valve is utilized to control the air flow rate to the room. A calibrated orifice with utube manometer is used to measure the air flow rate. At air opening inlet; a fine screen is used to create uniform distribution of air. Vertical velocity distribution inside the room is measured using hotwire anemometer device with accuracy of $5 \%$. A mechanism is used to move the hot-wire anemometer in the vertical direction. Actual velocity distribution at inlet opening is measured to be used as the inlet condition for numerical calculations. The vertical velocity is measured along the room vertical axis $(\mathrm{x} / \mathrm{L}=0.5)$ at three positions. These positions are located at different values of $\mathrm{z} / \mathrm{L}$ equal $1 / 3,1 / 2$, and $2 / 3$.

\section{RESULTS AND DISCUSSIONS}

The results of velocity distribution and turbulent kinetic energy are presented at two different sections as shown in Fig. 1. Theses sections are:

(i) Vertical section at the middle of the $z$-axis of the room at $\mathrm{z} / \mathrm{L}=0.5$ [middle-z plane].

(ii) Horizontal sections at the middle of the $y$-axis of the room at $\mathrm{y} / \mathrm{L}=0.5$ [middle-y plane].

The results are presented in terms of velocity vectors and contour lines of the turbulent kinetic energy for different turbulence models.

\subsection{Results at Middle-z Plane}

Figure 4 presents numerical results of velocity variations at the middle-z plane for the investigated four turbulent models. It can be observed that the air velocity has higher values at the opening of inlet. These higher values remain until air reaches the opposite wall of the inlet. After air collision with the opposite wall of inlet; part of the air stream flows down to the outlet opening and the other part moves towards the upper zone of the room. The part of air which moves in the upward direction creates a recirculation zone at the room corner. Small part of inlet air moves downward to the lower zone of the room and flows with apparently, low velocity toward the outlet opening. From the comparison between the results shown for different turbulence models in Fig. 4 , it can be seen that, the velocity distribution along the room width still constant value and keeping the same direction. Furthermore, the recirculation zone creates at the same position with the same intensity for the four tested turbulence models.

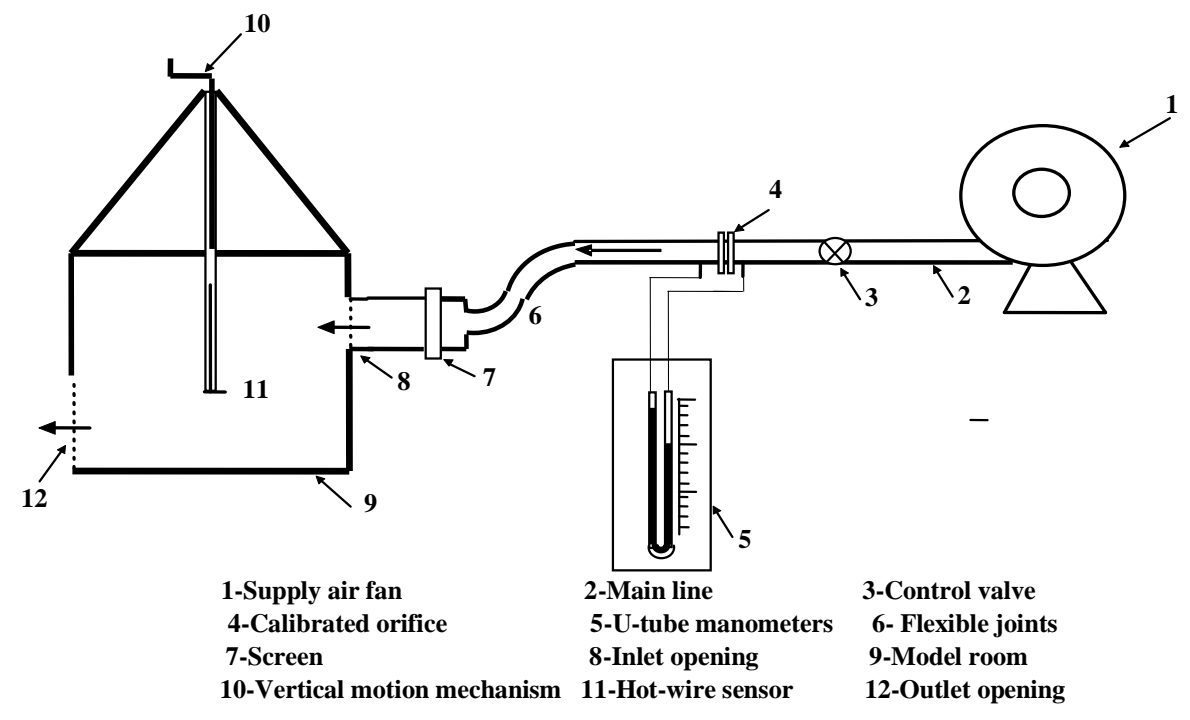

Fig. 3 The experimental setup 
The values of turbulent kinetic energy $(\mathrm{k})$ for the investigated models are shown in Fig. 5 at the middle-z plane. The figure shows that the maximum value of turbulent kinetic energy at the interface between two layers occurs in the same or opposite direction. At the joining zone of the recirculated air coming from the upper zone and that which comes from the core of recirculation zone at the room corner, the value of turbulent kinetic energy is obtained as $\mathrm{k} \approx 0.035 \mathrm{~m}^{2} / \mathrm{s}^{2}$. Zones without interface between layers such as inlet zone and in the lower part of the room the value of turbulent kinetic energy are markedly low. Also from the figure, it can be observed that the resulted values of kinetic energy obtained from Standard k- $\varepsilon$, Low-Re k- $\varepsilon$ and ChenKim models are kept equal along the room plane. However, the value of (k) of RNG in the recirculation zone is less than the corresponding values of the other models.

\subsection{Results at middle-y plane}

Figure 6 shows the velocity vectors at the middle-y plane $(\mathrm{y} / \mathrm{L}=0.5)$ for the tested turbulence models. It can be observed firstly here that the values of velocity all over the room space are small. This is rather expected because the tested plane lies under the inlet level. The high velocity is obtained here at the outlet opening. One can notice here the appearance of two recirculation zones at this plane. These zones lie on both sides of the outlet opening. In both standard k- $\varepsilon$ model and Low-Reynolds number one, the recirculation zones are similar. The recirculation zone resulted from RNG model is less than those of the standard k- $\varepsilon$ and Low-Re models. Chen-Kim model gives a size for the recirculation zone which coincides with those obtained from the standard k- $\varepsilon$ and RNG based k- $\varepsilon$ models.

The maximum value of turbulent kinetic energy lies at the center of the recirculation zone as shown in Fig. 7. The values of turbulent kinetic energy of recirculation zones for the three models (standard k$\varepsilon$, low-Re $\mathrm{k}-\varepsilon$, and Kim-Chen $\mathrm{k}-\varepsilon$ models) are approximately equal. RNG based $\mathrm{k}-\varepsilon$ model is different along the specified domain.

From the previous results, it can be concluded that results predicted by Chen-Kim are in considerable or good agreement with different turbulence models (standard k- $\varepsilon$, RNG model and low-Reynolds number model). To select one model from tested models some validation with previous experimental results will be performed in the next section.

To test the ability of Chen-Kim model for predicating the flow filed in ventilated rooms, the model will be employed in different geometries and different operating conditions. The numerical results will be compared with available experimental data.

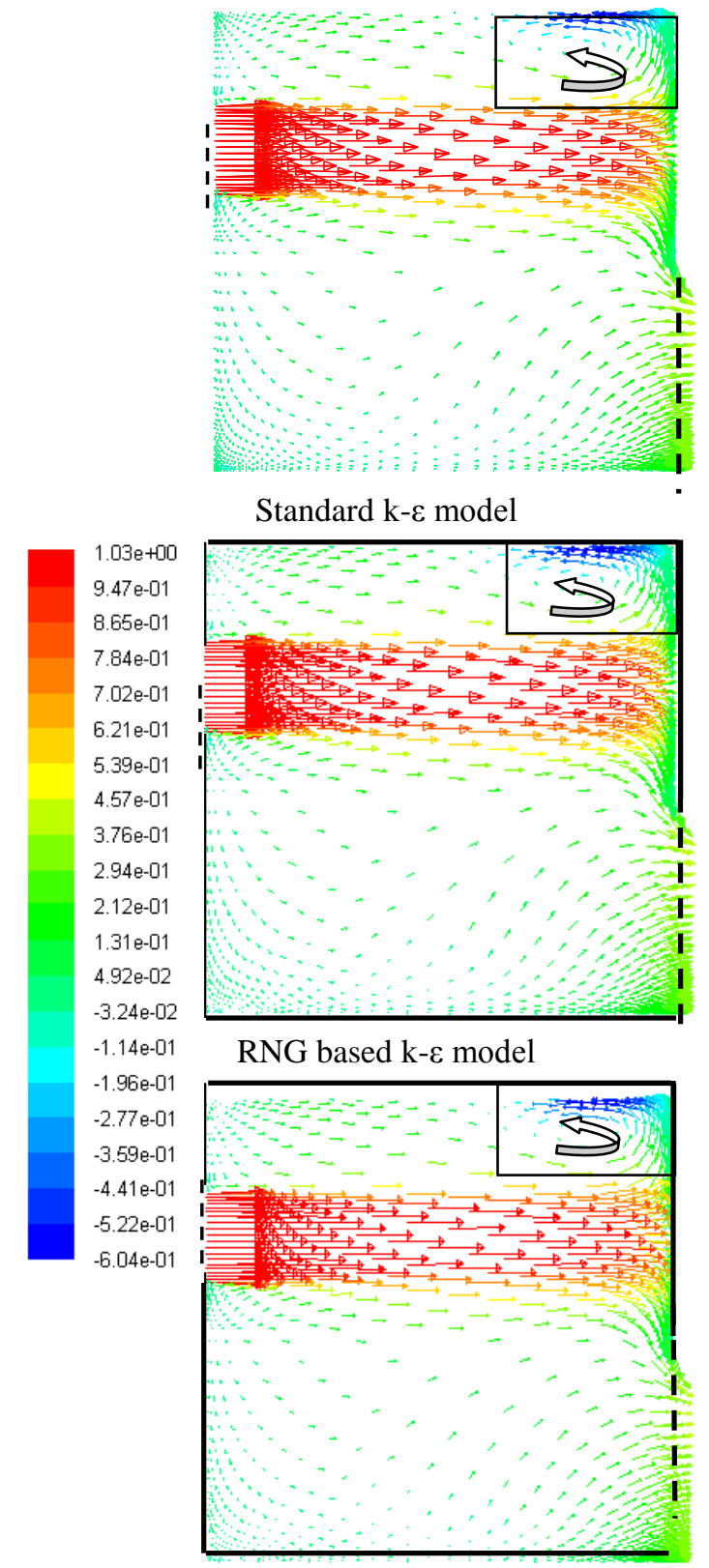

Low-Re k- $\varepsilon$ model

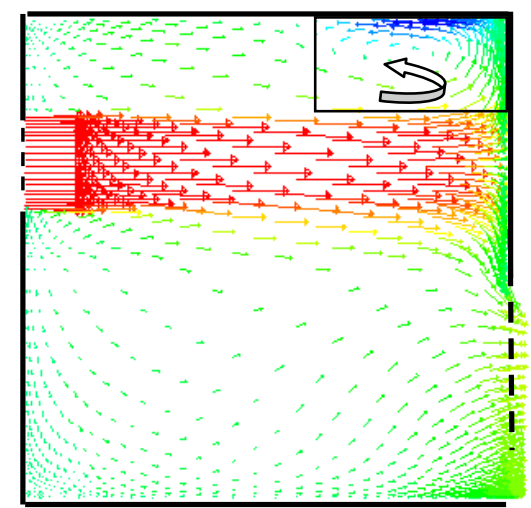

Chen- Kim k- $\varepsilon$ model

Fig. 4 Velocity vectors at the middle-z plane for different models 
T. I. Sabry, N. H. Mahmoud, A. A. Abdel-Hamied, A. A. Hussien, "Prediction of the Flow Field in Ventilated ..."

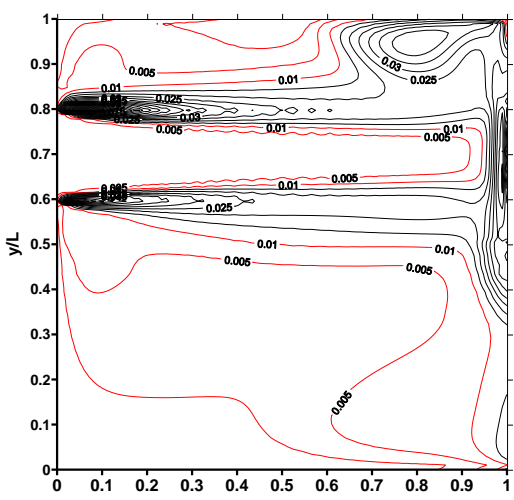

Standard k- $\mathrm{k}$ model

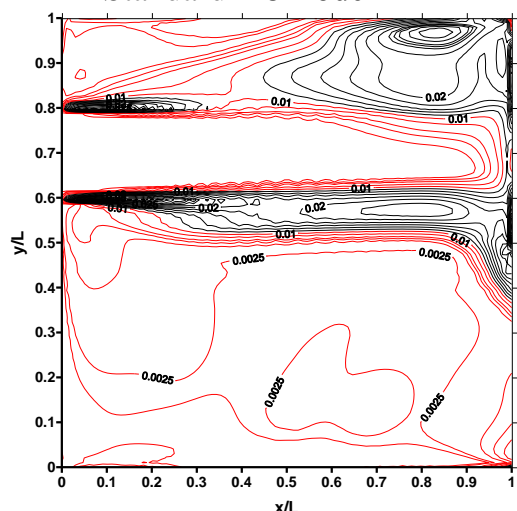

RNG based k- $\varepsilon$ model

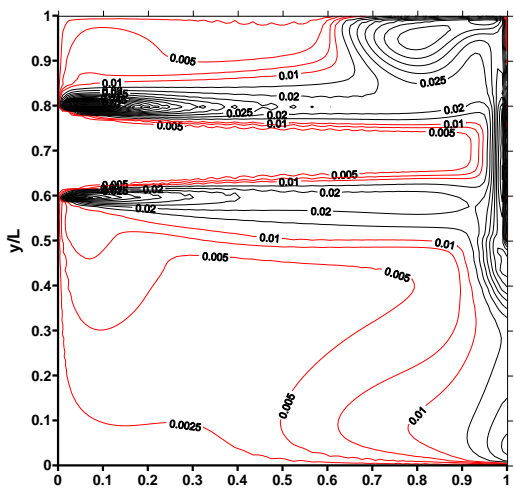

Low-Re k- $\varepsilon$ model

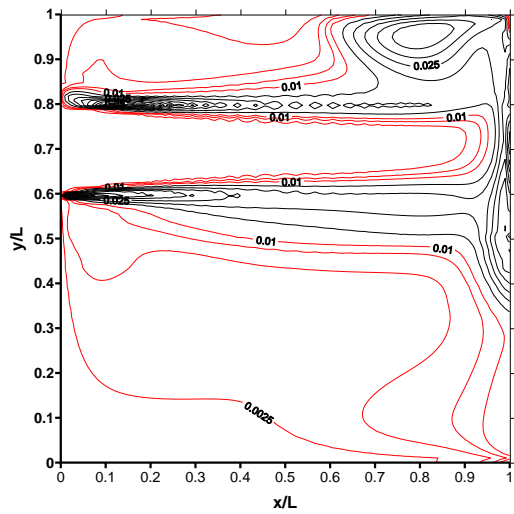

Chen- Kim k- $\varepsilon$ model

Fig. 5 Turbulent kinetic energy contours at the middle-z plane for different model

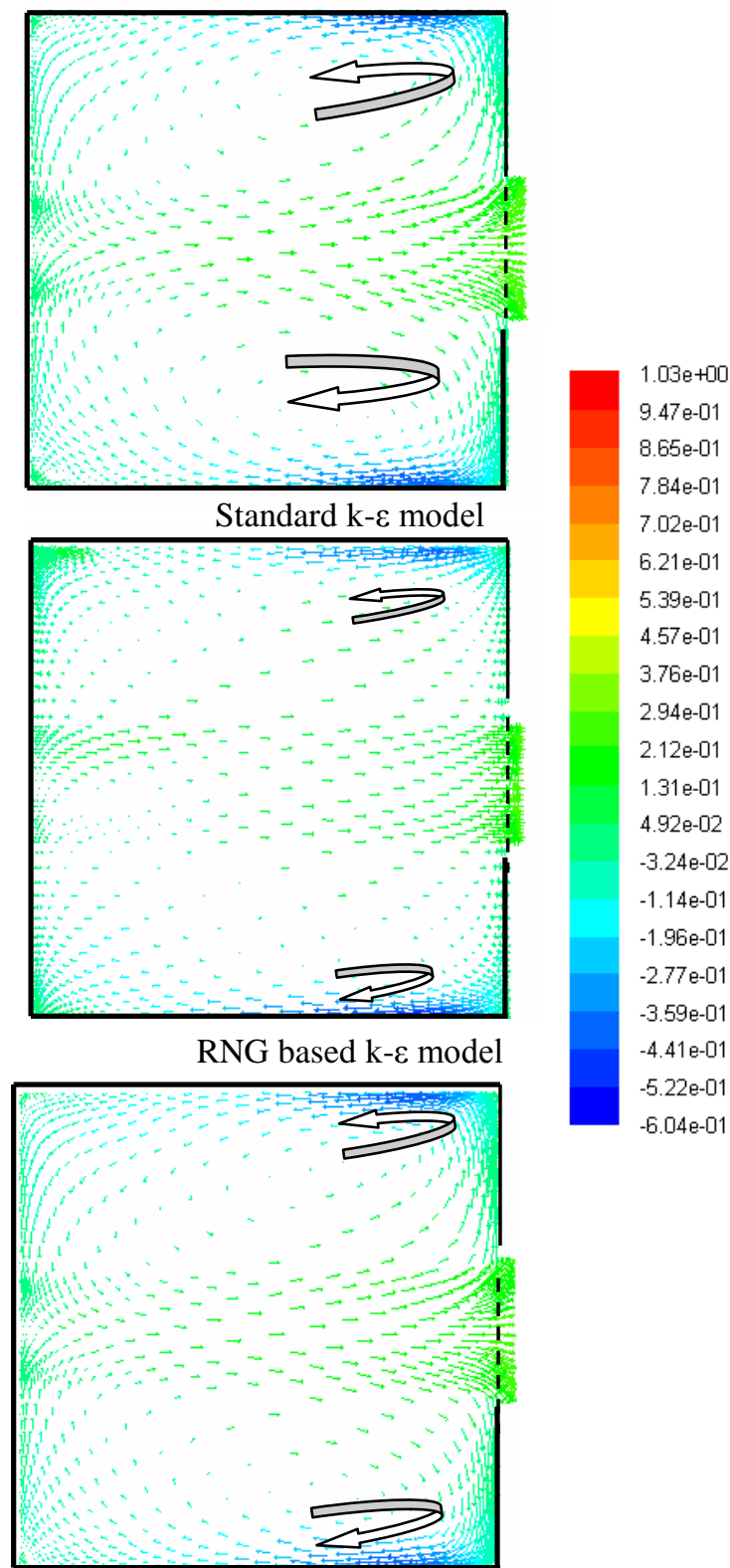

Low-Re k- $\varepsilon$ model

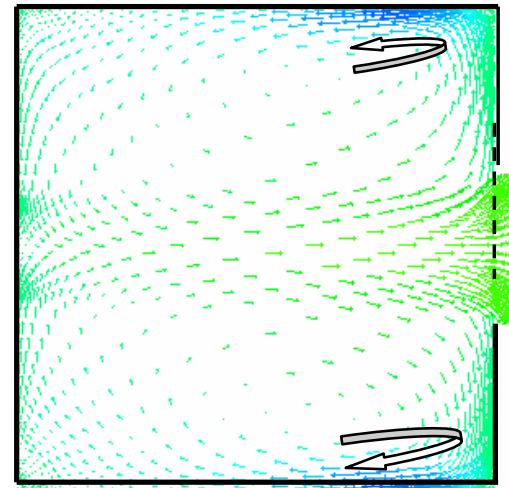

Chen- Kim k- $\varepsilon$ model

Fig. 6 Velocity vectors at the middle-y plane ( $\mathrm{y} / \mathrm{L}=0.5$ ) 


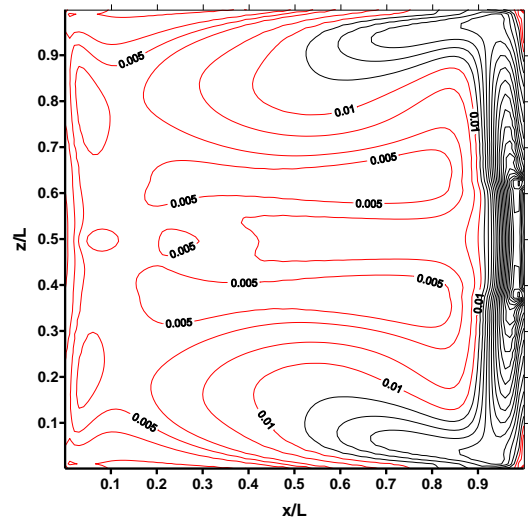

Standard k- $\varepsilon$ model

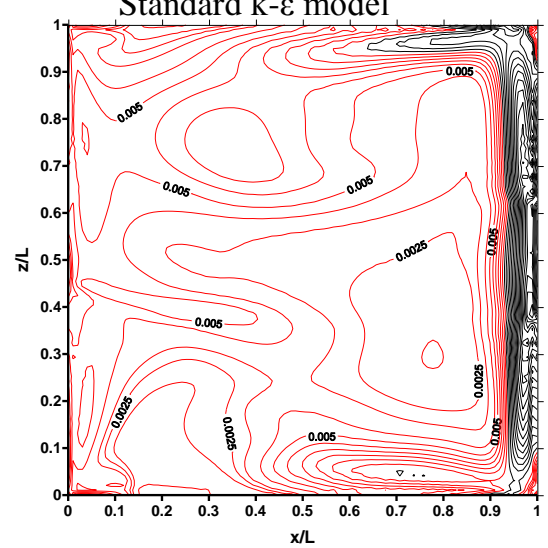

RNG based $\mathrm{k}-\varepsilon$ model

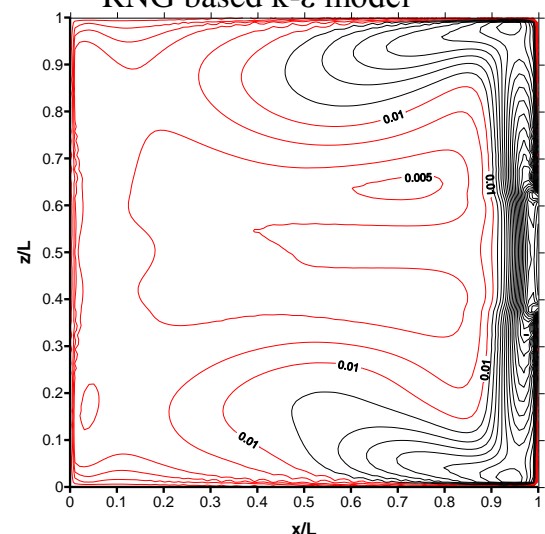

Low-Re k- $\varepsilon$ model

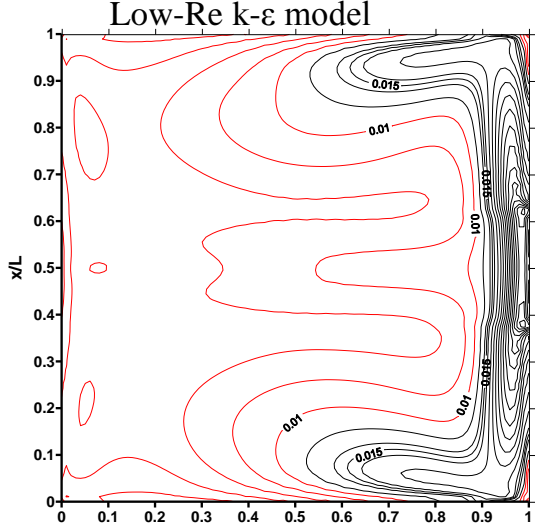

Chen-Kim k- $\varepsilon$ model

Fig. 7 Turbulent kinetic energy contours at middle-y plane for different model
Comparison between numerical results of $\mathrm{u}$-velocity distribution for different turbulence models with published experimental data [8] is illustrated in Fig. 8. From this figure, it can be observed that Chenmodel is in a fair agreement with the measured velocity distribution especially near the wall. Also, Fig. 9 shows agreement between Chen-Kim model and other experimental data [18].

The different turbulence models are also applied on a different geometry as shown in Fig. 10. From the figure it can be observed that, a rather better agreement between Chen-Kim model and published experimental data [19].

For extra more validation, some experimental results are obtained using a complete setup system of forced ventilation as shown in Fig. 3. From comparison between numerical results and measured data shown in Fig. 11, it can be observed that the four employed turbulence models give acceptable coincidence with experimental data. Also, a comparison between results due to Chen-Kim and RNG models with the measured data is given in Fig. 12. It can be noticed that Chen-Kim model closely predicts experimental results more than RNG model.
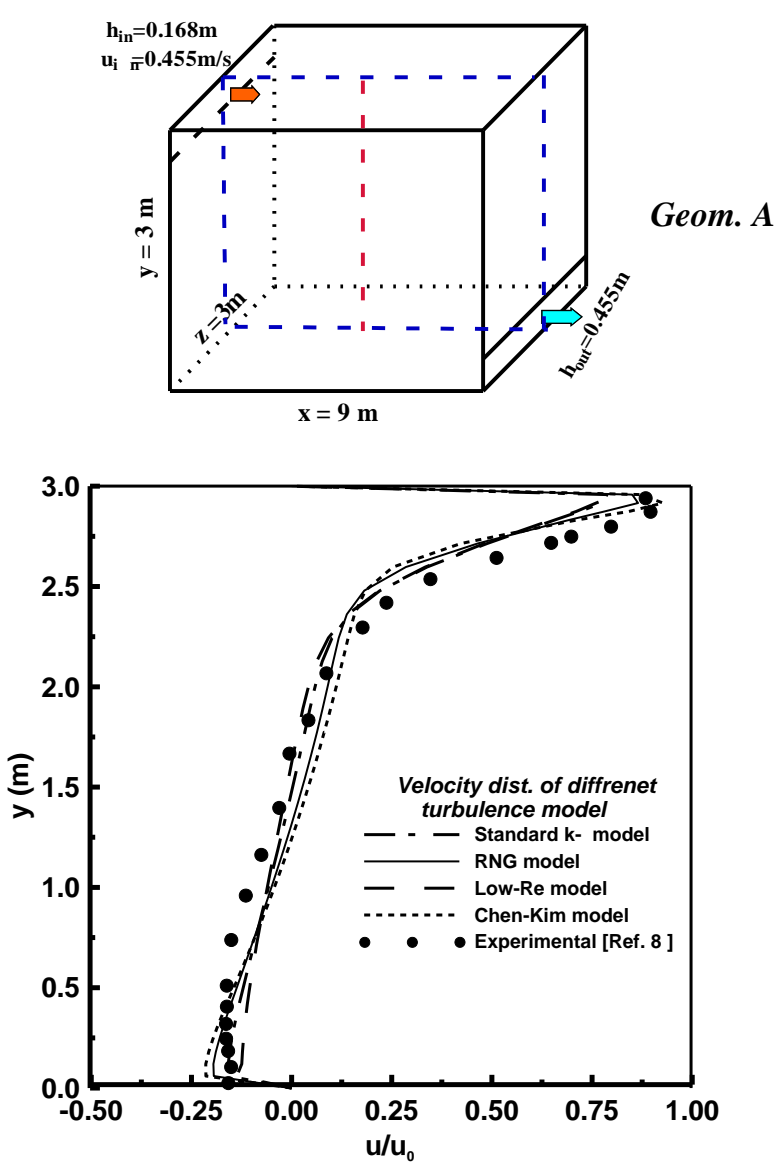

Fig. 8 Comparison between different models with experimental data [8] for geometry-A 


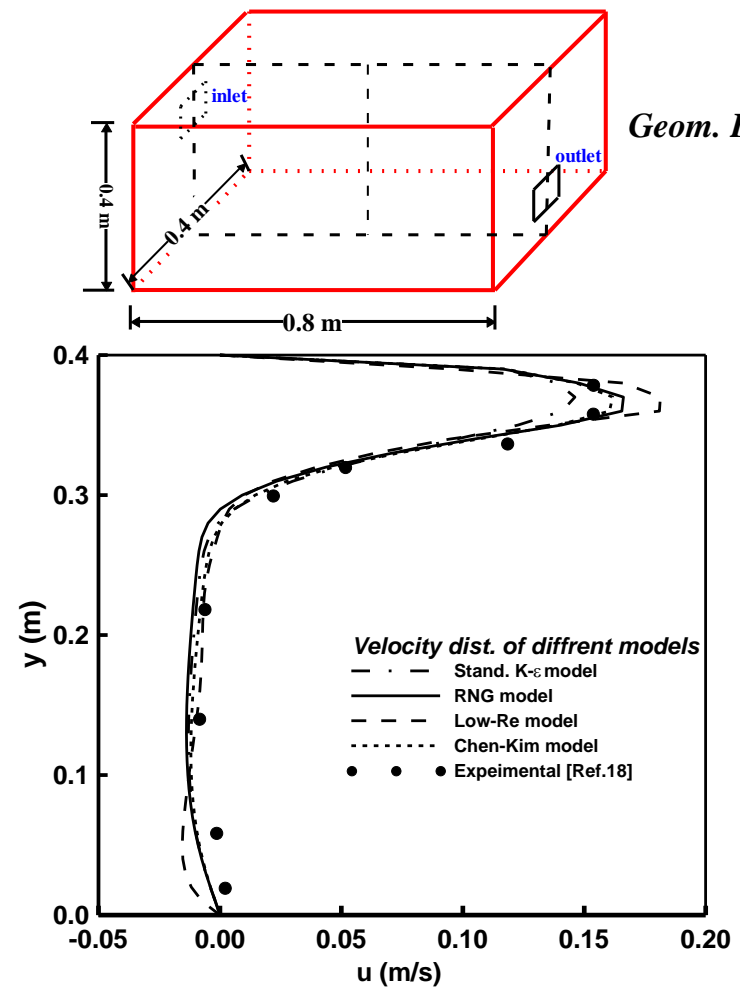

Fig. 9 Comparison between different models with experimental data [18] for geometry-B

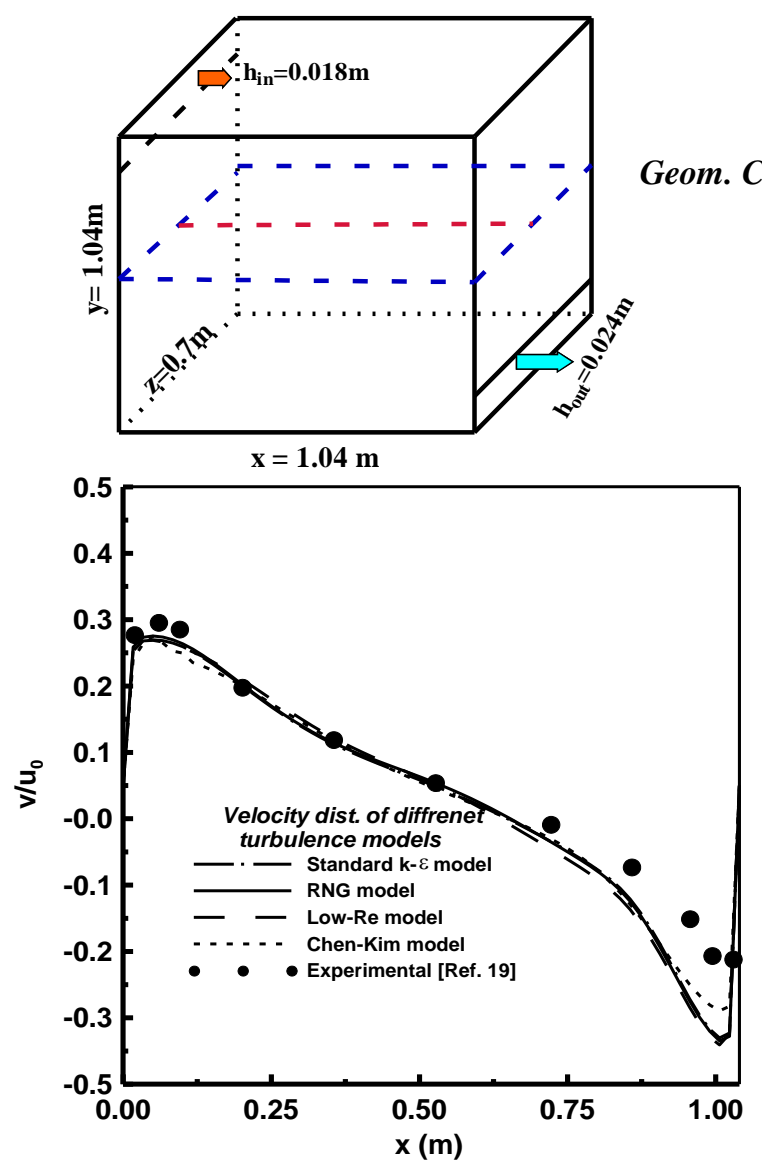

Fig. 10 Comparison between different models with experimental data [ Ref.19] for geometry-C

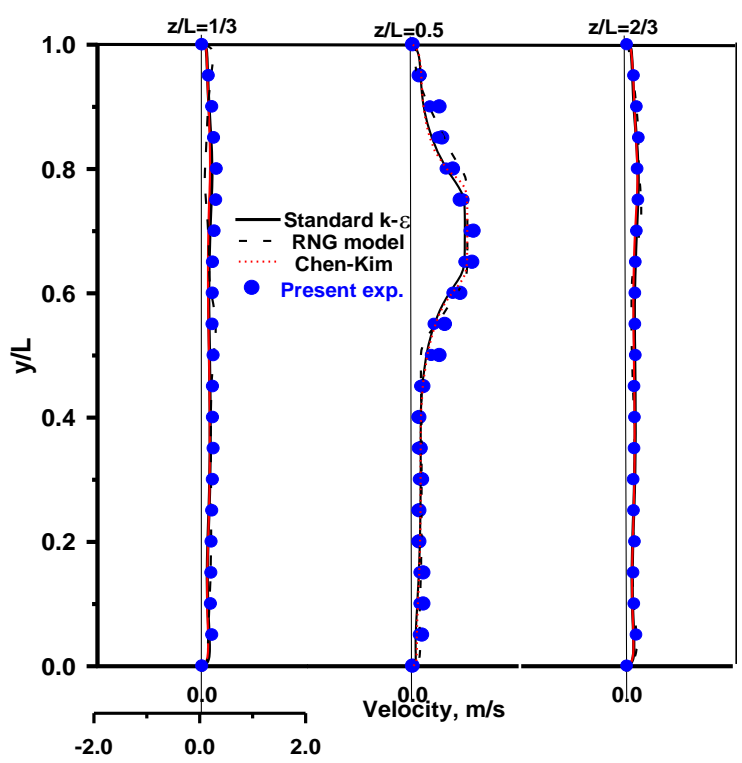

Fig. 11 Vertical velocity distribution obtained experimentally and also using different numerical models

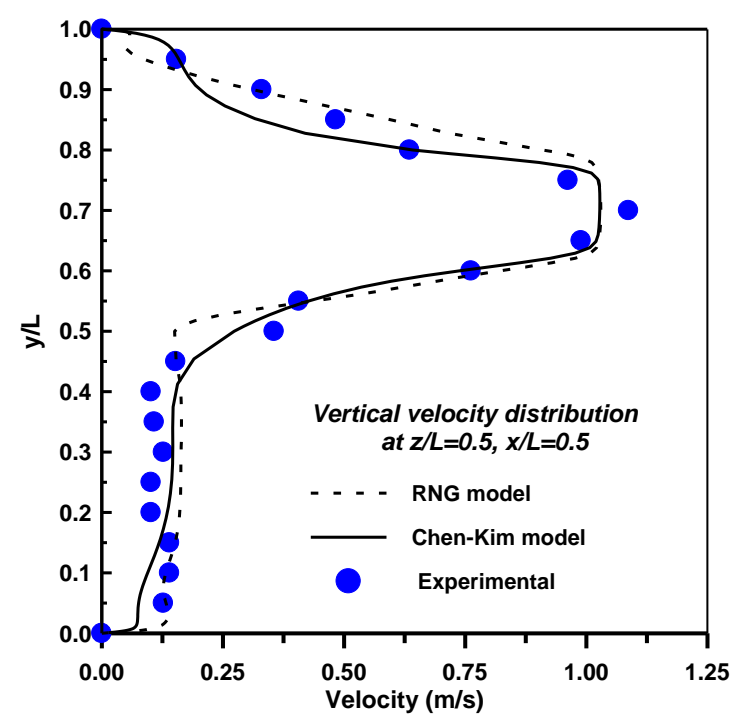

Fig. 12 Comparison between numerical and experimental results

\section{CONCLUSIONS}

The different turbulence models of two-equations $k-\varepsilon$ models can predict the flow field inside ventilated rooms. Some turbulence k- $\varepsilon$ models are not widely used to predict the flow field in ventilation studies. These models include Chen-Kim model. In the present study, Chen-Kim model is programmed and used to predict the flow field in ventilated rooms. Comparison between numerical results of Standard $\mathrm{k}-\varepsilon$, RNG, Low-Reynolds number and Chen-Kim models revealed the following: 
1- Both Standard k- $\varepsilon$ and Low-Re number models give approximately the same results.

2- Chen-Kim model based on $\mathrm{k}-\varepsilon$ model gives nearest results to the published experimental data and the present measured data.

3- Near the walls, the numerical results of Chen-Kim model are better than the numerical results of RNG model.

It can be concluded that, the extended standard $\mathrm{k}-\varepsilon$ (Chen-Kim) model can be used to predict the air flow field inside closed rooms of forced ventilation systems with considerable accuracy compared with other different turbulence models.

\section{NOMENCLATURE}

$\begin{array}{llc}\mathrm{g} & \text { Gravity acceleration } & \left(\mathrm{m} / \mathrm{s}^{2}\right) \\ \mathrm{H} & \text { Height of model in y-direction } & (\mathrm{m}) \\ \mathrm{I} & \text { Turbulence intensity } & - \\ k & \text { Turbulent kinetic energy } & \left(\mathrm{m}^{2} / \mathrm{s}^{2}\right) \\ \mathrm{L} & \text { Length } & (\mathrm{m}) \\ p & \text { pressure } & (\mathrm{Pa}) \\ p r & \text { Production rate } & \left(\mathrm{kg} / \mathrm{m}_{\mathrm{s}} \mathrm{s}^{3}\right) \\ \operatorname{Re} & \text { Reynolds number } & - \\ \mathrm{T} & \text { Temperature } & (\mathrm{K}) \\ \mathrm{t} & \text { Time } & (\mathrm{s}) \\ u & \text { Velocity component in x-direction } & (\mathrm{m} / \mathrm{s}) \\ v & \text { Velocity component in y-direction } & (\mathrm{m} / \mathrm{s}) \\ w & \text { Velocity component in z-direction } & (\mathrm{m} / \mathrm{s})\end{array}$

\section{Greek symbols}

$\varepsilon \quad$ Turbulent dissipation rate $\quad\left(\mathrm{m}^{2} / \mathrm{s}^{3}\right)$

$\Phi \quad$ Scalar quantity

$\mu \quad$ Dynamic viscosity

$\rho \quad$ Density

$\Gamma \quad$ Diffusion coefficient

$\tau_{\mathrm{w}} \quad$ Wall shear stress

$\begin{array}{ll}\text { Subscript } \\ \mathrm{a}_{\mathrm{v}} & \text { average value } \\ \mathrm{t} & \text { turbulent } \\ \mathrm{e} & \text { effective } \\ 0 & \text { inlet } \\ \mathrm{W} & \text { wall }\end{array}$

\section{Abbreviations}

CFD Computational fluid dynamics

RNG Re-normalization group

$(\mathrm{kg} / \mathrm{m} . \mathrm{s})$

$\left(\mathrm{kg} / \mathrm{m}^{3}\right)$

$(\mathrm{kg} / \mathrm{m} . \mathrm{s})$

$\left(\mathrm{N} / \mathrm{m}^{2}\right)$

\section{REFERENCES}

[1] Davidson, L., "Calculation of the Velocity and Concentration Fields in a Clean Room", Nordiska R-foreningens Proceedings-Odenese, 1998.

[2] LU, W., and Howarth, A. T., "Numerical Analysis of Indoor Aerosol Particle Deposition and Distribution on Two-Zone Ventilation System", Building and Environment, Vol. 31, No. 1, pp. 41-50, 1996.

[3] Chen, Q., "Comparison of Different k- $\varepsilon$ Models for Indoor Air Flow Computations", Numerical Heat Transfer, Part B, Vol. 28, pp. 353-369, 1995.

[4] Xu, W., and Chen, Q., "A Two-Layer Turbulence Model for Simulating Indoor Air Flow, Part I: Model Development", Energy and Building, Vol.33, pp. 613-625, 2001.

[5] Xu, W., and Chen, Q., "A Two-Layer Turbulence Model for Simulating Indoor Air Flow, Part II: Applications", Energy and Building, Vol. 33, pp. 627-639, 2001.

[6] Davidson, L., and Nielsen, P. V., "Large Eddy Simulations of the Flow in a Three-Dimensional Ventilated Room", 5th Int. Conf. on Air Distributions in Rooms (ROOMVENT 96), Vol. 2, pp. 161-168, Yokohama, Japan, July 17-19, 1996.

[7] Chung, K .C., "Three-Dimensional Analysis of Air Flow and Contaminant Particle Transport in a Partitioned Enclosure", Building and Environment, Vol. 34, pp. 7-17, 1999.

[8] Zhang, W., and Chen, Q., "Large Eddy Simulation of Indoor Air flow with a Filtered Dynamic Subgrid Scale Model", International Journal of Heat and Mass Transfer, Vol. 34, pp. 3219-3231, 2000.

[9] Nikas, K. S., Nikolopoulos, N., and Nikolopoulos, A., "Numerical Study of a Naturally Cross-Ventilated Building", Vol. (42), pp. 422-432, 2010.

[10] Savrakakis, G. M., and Markatos, N. C., "Simulation of Air flow in One- and Two-Room Enclosures Containing a Fire Source", International Journal of Heat and Mass Transfer, Vol. 52, pp. 2690-2703, 2009.

[11] Chen, Y. S., and Kim, S. W., "Computation of Turbulent Flows using an Extended k- $\varepsilon$ Closure Model", Interim Report (NASA- CR-179204), 1987.

[12] Bartzanas, T., Kittasa, C., Sapounasc, A. A., and Nikita-Martzopoulouc, C., "Analysis of Air flow through Experimental Rural buildings: Sensitivity to Turbulence Models", Bio Systems Engineering, Vol. 97, pp. 229 - 239, 2007. 
[13] Versteeg, H. K., and Malalasekera, W., " An Introduction to Computational Fluid Dynamics: The Finite Volume Method", Longman Scientific \& Technical, England, 1995.

[14] Libby, P. A., "Introduction to Turbulence ", Taylor\& Francis, 1996.

[15] Hrenya, C. M., Bolio, E. J., Chakrabarti, D., and Sinclair, J. L., "Comparison of Low Reynolds Number K- $\varepsilon$ Turbulence Models in Predicting Fully Developed Pipe Flow", Chemical Engineering Science, Vol. 50, No.12, pp. 19231941, 1995.

[16] Bredberg, J., "Internal Report 00/4; On the Wall Boundary Condition for Turbulence Models",
Chalmers University of Technology, Sweden, 2000.

[17] Fluent user guide, Version 6.3, 2006.

[18] Alvin, C. K., and Chen, F., "Modeling Particle Deposition and Distribution in a Chamber with a Two-Equation Reynolds-Averaged NavierStokes Model", Aerosol Science, Vol.37, pp. 1770-1780, 2006.

[19] Zhang, W., and Chen, Q., "Large Eddy Simulation of Natural and Mixed Convection Air flow Indoors with Two Simple Filtered Dynamic Subgrid Scale Models", Numerical Heat Transfer, Part A: Applications, Vol.37, No.5, 447-463, 2000. 